\title{
Managing the risk of emergency situations caused by staff at thermal power plants
}

\author{
Alexander Kolesnikov ${ }^{1}$, Tatiana Kokodey ${ }^{2}$, Tatiana Lomachenko ${ }^{3}$, Vasiliy Makarov ${ }^{4}$, Sofia \\ Pospelova ${ }^{3, *}$ \\ ${ }^{1}$ St. Petersburg State University of Aerospace Instrumentation, Bol'shaya Morskaya ul., 67, 190000, \\ St. Petersburg, Russia \\ ${ }^{2}$ Sevastopol State University, ul. Universitetskaya, 33, 99026, Sevastopol, Russia \\ ${ }^{3}$ Sevastopol Affiliate of the Russian Economic University by G.V. Plekhanov, Sevastopol, Russia \\ ${ }^{4}$ St. Petersburg Polytechnical University of Peter the Great, Politekhnicheskaya ul., 21, 194021, St. \\ Petersburg, Russia
}

\begin{abstract}
Optimization of power plant operation in start and stop modes is an important task aimed at increasing the reliability and efficiency of its operation. The purpose of development of the new organizational mechanism is reduction of losses connected with incorrect actions of personnel during launching and shutdown operations of Steam-Gas furnaces of thermal power stations. The work is done on the example of one of the power plants of a large generating company. Implementation has confirmed the high efficiency of innovation. Total cost of project implementation at one station is estimated at the rate of 1.4 million rubles and the economic effect of the pilot project implementation in two years was estimated at 5.6 million rubles. It is also noted that further research is required to perform economic calculations for clarification as to which one of the new methodological approaches should be developed in the future. Conclusion was made that, first, regulation and control of personnel actions at the workplace is actually the first example of the distribution of the well-known Kaizen system and its modifications to a new specific area - energy generation. Second, the presented development can be a technological platform for further increase of the level of automation of operation of steam-gas and steam-power plants in non-stationary modes, up to full digitalization of control operation of thermal power plants.
\end{abstract}

\section{Introduction}

The most important tasks facing the electric power industry are: to provide reliable energy supply to industrial enterprises and population, to build up productive capacity, to reduce energy costs, and to modernize production equipment using modern technologies. Energy companies, addressing the issue of improving the efficiency of electric and thermal power generation, today make an emphasis on input capacities that use steam-gas generation, as well as on the maximum of automation processes, which ensures the final "Digitalization" of energy production.

\footnotetext{
* Corresponding author: sofia_valentin@mail.ru
} 
In recent years, technological Process Control automation systems (PCAS) and the equipment of energy facilities have been improving rapidly. Such functions of PCAS as remote control of actuators, technological locks, and protection and signaling have recently been primarily by relay automation. Today, the majority of stations operate MICROPR.

The purpose of this paper is to develop a system of standardization and control of operational personnel during the launch operations of Steam-gas installations.

\section{Materials and methods}

Five-year (from 2013 to 2017) of experience of operation of three steam-gas installations in the considered generating company showed that staff errors accounted for for 18 accidents. As a result, the company suffered significant economic losses - more than 300 million Rubles.

The consequences of accidents vary considerably depending on the type of power plant, time and duration of interruptions, availability and size of reserves and other factors. They can be of a social, ecological and techno-economic nature. We consider the last first.

To determine the economic damage caused by accidents, the technical characteristics of the power plant equipment and their performance at the Federal Wholesale Market for Electrical Energy Capacity (FWMEEC), taken from the reports of the administrator of the trade system and the system operator [2], are used as initial data.

The main component of the economic damage caused by the cessation or restriction of the supply of electricity and power to the FWMEEC, as well as thermal energy, is loss of profits. Its value is defined as the difference between the expected and actual volumes of the sale of electricity and heat (in value terms) in the market, minus the cost of fuel needed to produce the specified volume of electricity. The damage also includes an increase in the cost of fulfillment of obligations for the supply of electricity under regulated and free contracts (purchased at the next day's cost) and a negative result of work on balance market for the period of elimination of the accident The magnitude of the damage to the power supply is defined as the actual reduction in the value of the delivered power due to failure to comply with the requirements to maintain the readiness of the generating equipment to generate electricity in accordance with Annexes to the contract of accession to the trading system of the wholesale market - the rules of the FWMEEC. The increase in the cost of production of thermal energy in comparison with the option of planned operation of the unit and the selections from the turbine is associated with the need to transfer its output to the peak water boiler house. There are also obvious irretrievable losses of the main production funds and the cost of repair and restoration work.

During the analysis of the reasons of staff errors during operation of steam-gas installations, the following were revealed:

-Insufficient experience of operation of the junior technical staff of the shift;

-Inattentiveness in situations which ordinarily require attention;

-incomplete instructions for the operation of basic and auxiliary equipment;

-Lack of oversight mechanisms to control and monitor the work of operational personnel;

-Lack of normative and technical documentation on the operation of the GSI.

The psycho-physiological basis of most of the reasons listed above is obvious. In the given generating company more extensive studies of the psychology of erroneous actions of personnel were conducted simultaneously, the results of which are presented in the table. They are fully consistent with the findings of our study. 
Table 1. Psychological reasons of occurrence of erroneous actions of the personnel and infringements of normal course of processes.

\begin{tabular}{|c|c|c|c|c|c|c|c|}
\hline \multirow{2}{*}{ Causes of accidents } & \multirow{2}{*}{$\begin{array}{c}\text { Personal } \\
\text { characteristics }\end{array}$} & \multicolumn{6}{|c|}{ Percentage ratio, $\%$} \\
\hline & & 2013 & 2014 & 2015 & 2016 & 2017 & average \\
\hline Personal inattention & \multirow{2}{*}{ inattention } & \multirow{2}{*}{33} & \multirow{2}{*}{20} & \multirow{2}{*}{31} & \multirow{2}{*}{33} & \multirow{2}{*}{26} & \multirow{2}{*}{29} \\
\hline Mistaken action & & & & & & & \\
\hline Unverified incoming information & $\begin{array}{l}\text { Inaccurate } \\
\text { information transfer }\end{array}$ & 3 & 5 & 4 & 3 & 10 & 5 \\
\hline Insufficient control by management & \multirow{2}{*}{ Weak control } & \multirow{2}{*}{17} & \multirow{2}{*}{25} & \multirow{2}{*}{27} & \multirow{2}{*}{17} & \multirow{2}{*}{26} & \multirow{2}{*}{22} \\
\hline Unprepared workplace & & & & & & & \\
\hline Uncoordinated actions of personnel & \multirow{8}{*}{ Self-confidence } & \multirow{8}{*}{17} & \multirow{8}{*}{23} & \multirow{8}{*}{12} & \multirow{8}{*}{10} & \multirow{8}{*}{13} & \multirow{8}{*}{15} \\
\hline Violation of discipline & & & & & & & \\
\hline Undocumented work & & & & & & & \\
\hline Wrong assessment of possibilities & & & & & & & \\
\hline Not following the instructions & & & & & & & \\
\hline Untimely response & & & & & & & \\
\hline $\begin{array}{l}\text { Unauthorize bypassing of safety } \\
\text { sensors }\end{array}$ & & & & & & & \\
\hline Adding job duties & & & & & & & \\
\hline $\begin{array}{l}\text { Insufficient knowledge and weak } \\
\text { preparation }\end{array}$ & $\begin{array}{l}\text { Insufficient } \\
\text { knowledge }\end{array}$ & 13 & 3 & 0 & 7 & 5 & 7 \\
\hline $\begin{array}{l}\text { Inaction } \\
\text { Negligent attitude }\end{array}$ & Formalism & 27 & 17 & 0 & 30 & 21 & 19 \\
\hline $\begin{array}{l}\text { Lack of coordinating actions from } \\
\text { management, insufficient instruction } \\
\text { in the consequence of actions }\end{array}$ & \multirow[t]{2}{*}{ External factors } & \multirow[t]{2}{*}{0} & \multirow[t]{2}{*}{7} & \multirow[t]{2}{*}{8} & \multirow[t]{2}{*}{0} & 0 & 3 \\
\hline Inoperable alarms & & & & & & & \\
\hline
\end{tabular}

As can be seen from the table, the main personal qualities that formed the basis of erroneous actions of staff were self-confidence and inattention, as well as weak management control.

Self-confidence is usually due to neglect of the application of the previously studied rules and instructions, and inattention, on the contrary, is characterized by the lack of thorough information processing by operational personnel. In order to avoid these reasons, the personnel skills level and the strength of knowledge, the availability of clear instructions and control of their performance by management should be worked out, so that during dangerous situations the staff can act according to these Instructions to ensure their safety and to eliminate the causes of accidents.

Significant economic damage has led to an acute need to address this problem.

The object of consideration is a steam-gas installation of PGU-450, which consists of two gas turbines GTE-160 and Steam turbine T-125/150, total electric power of $425 \mathrm{MW}$ and heat-290 Gkal/h. The main equipment is manufactured Energy-Engineering Plants Inc.: "Power Machines" and "Podolskiy Factory Inc.". 
Taking into account the number of accidents on the steam-gas plants caused by the "human factor", it was decided to apply a set of measures to regulate and strengthen the control of operations of operational personnel responsible for practical actions on startingstopping of the GSI [3].

Start is performed by the command of the System operator. The general management of the launch is carried out by the shift supervisor of the station operational service (Fig. 1). He coordinates the operations of shift workers of workshops, enforces the start-up standards, alerts repair staff to troubleshoot problems, and provides operational communication with the managers of the company "Heat Network" and Rally organizations.

The shift supervisor of the boiler and turbine workshop carries out operative and technical management of the start, and provides start-up instructions. The shift supervisor of the chemical workshop (in Figure 1 is not specified) provides the required quantity and quality of the desalinated water supply, maintains a detailed narrative journal listing the indicators of water-chemical mode of the equipment and technological environment settings. He is responsible for the economical expenditure of water and chemical agents. The managers of the shifts of the heat automatics and measurements department and the electrical shop ensure the uninterrupted operation of the equipment under their control and, thus, participate in the provision of start-up and resource saving standards.

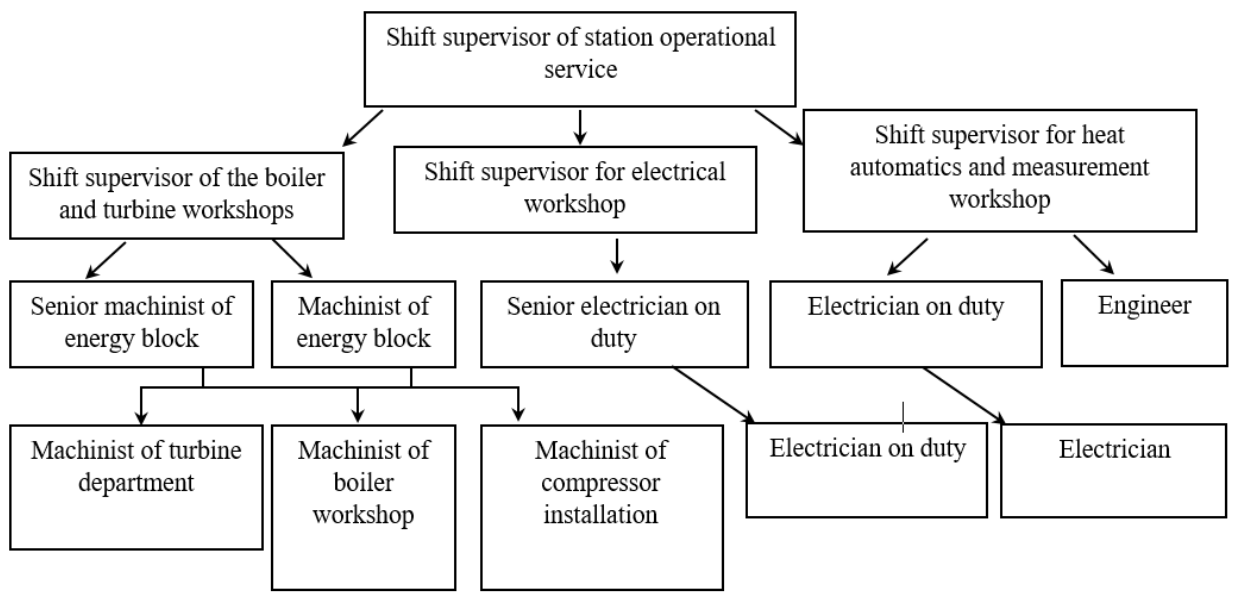

Fig. 1. The structure of operational personnel involved in the commissioning of the unit of the GSI.

It should be noted that the actions of the shift chiefs are currently changing widely, and the start-up is conducted in different ways. But in contrast to the actions of the Chiefs of department shifts (level 2), performed from the control Panel, which has a written checklist, the operations of the junior technical staff ( 3 and 4 levels) is not possible to control, and the impact of the "human factor" here becomes decisive. It is unclear, for example, in what order the senior unit operator performs operations at the Block Control Panel, as well as what operations he delegates to the subordinates. He gives commands to the crawler operators from the Block shield, and their performance is confirmed by radio communication, which suggests that the information exchange between them takes place on a trusting basis. All this is an essential prerequisite for the emergence of ad hoc actions and the occurrence of emergency situations.

While searching for possible solutions to this problem, we analyzed industries analysis of industries, which also operate complex engineering systems on which depend on the lives and well-being of many people. The industry is aviation. In aviation, as in the energy sector, for more than 50 years, gas turbine systems are being operated. A special document 
- "Check-list" (Fig. 2) is used to ensure reliable operation of the equipment in aviation. A check-list is a list of operations performed in accordance with the established procedure and mandatory for execution to ensure a high degree of reliability of operation of a complex technical system [4].

\section{Results of research}

The introduction of check-lists was considered practical for application at thermal power plants for procedures of start and stop of blocks of GSI for personnel of 3rd and 4th levels. For this purpose, it was necessary to develop check-lists for each operative worker, and also the system of control for fulfillment of requirements of these documents.

A working group was created in the energy company under consideration which performed the following works:

- Analysis of operational documentation and archives of actions,

- An analysis of the operating instructions of the main and auxiliary equipment was conducted,

- studied the experience of personnel in launching operations at the GSI.

The analysis of personnel actions was carried out by accompaniment of participants of launch and shut-down of all competed actions.

Further, the fixed algorithm was subjected to detailed parsing and analysis of the entire working Group to identify the missing/superfluous actions. The result of the group's work is expanded and operational register statements for all participants of the 3rd and 4th levels.

The starting list is a document rigidly regulating the algorithm of personnel actions at each workplace. All actions performed by the Senior Unit operator (Level 3) are regulated in the operational launch statement. As they are executed, a corresponding mark is put in the statement. Each 4-level crawler has an extended starter list. After completing each action, he makes an operative report to the senior operator of the power unit and passes to the next step only upon receiving permission. When a block of operations is executed, the worker places his mark on the statement. After completion of the start or stop procedure, all the statements are sent to the production and technical department where the analysis of completeness of performed actions, time of operations taking place deviations, trends, etc. received Data for control is also compared with SOUTHP information, with records from the journals and archives of staff at levels 1 and 2.

In case of emergency, the employees of the PTO together with the established Commission carry out the corresponding analysis of the launch statements and when detecting improper actions of the personnel apply appropriate sanctions. If the drafting of the statement itself is inaccurate, it is amended.

An important outcome of the implementation of the regulatory framework and enhanced control staff was to increase its responsibility in moving from a collective responsibility to an individual one. The introduction helped to refine the system of material compensation of labor. The appearance of new documents also required the development of the order of their movement, accounting, storage and adjustment, compiling a list of persons responsible for completeness and reliability of the information provided. The scanned originals of the start registers are the appropriate database available for remote use by all interested parties.

The introduction of the new system was preceded by the training of staff, and during the implementation of selective control of staff actions was conducted through unscheduled audits. One of the members of the Working Group controlled the actions of the senior operator of the unit, and the second was attached selectively to one of the driver-crawler, which allowed on the one hand to check the compliance with the technological requirements of the statements, and, on the other hand, opportunities for further improvement. 


\section{Perspectives for further research}

Since the introduction of the pilot project at one of the company's stations in early 2016, no accidents have been reported by the staff. At the end of 2016, the shareholders of the company decided to replicate the project at other facilities generating energy, both steamgas plants and steam-powered. Work in this direction is already underway.

Total cost of project implementation at one station is estimated at the rate of 1.4 million Rubles. The economic effect of the pilot project implementation in two years was estimated at 5.6 million Rubles.

Moreover, it was revealed that the solution described could be a technological platform for further increase of the level of automatic control of the operation of steam-gas and steam-power plants in non-stationary modes, up to the full digitalization of thermal power plant operation. This, in turn, will require further research.

In its turn, this innovation showed that the system of documenting and controlling personnel actions at the workplaces is a prime example of the Kaizen system and its modifications in this new energy generation arena. It also opens up wide prospects for further research.

Total cost of project implementation at one station is estimated at the rate of $1.4 \mathrm{mln}$. rubles and the economic effect of the pilot project implementation in two years was estimated at 5.6 million. rubles. Economic calculations should be clarified, for which new methodological approaches should be develop.

\section{References}

1. N.K. Vydrin, V.M. Makarov, Scientific and practical conference with international participation "Industrial Policy in Digital economy: Problems and Prospects ", 427435 (2017)

2. Rules of technical operation of electrical stations and networks of the Russian Federation from 153-34.20.501-2003

3. Guidance on the analysis of the quality of start (shutdown) of the main equipment of the CHP Rd 153-34.0-20.585-00

4. A. Haande, Check-list. How to avoid silly mistakes that lead to fatal consequences (2009)

5. O. Novikov, V. Makarov, Collection of Materials XI international scientific and Practical Conference, 65-67 (2017) 